\title{
Penyebab Kerusakan Electro Motor Oil Max Pump pada Mesin Induk di KM. Dharma Kartika IX
}

\author{
Andi Hendrawan ${ }^{1}$, Siswadi $^{2}$, Supari ${ }^{3}$, Ragil Ajun Abdilah Al Khomsi ${ }^{4}$ \\ ${ }^{1,4}$ Akademi Maritim Nusantara Cilacap \\ ${ }^{2}$ Unimar AMNI Semarang \\ ${ }^{3}$ Fakultas Teknik Universitas Semarang \\ andi_hendrawan@gmail.com
}

Diterima 25 Januari 2021, direvisi 05 Februari 2021, diterbitkan 08 Maret 2021

\begin{abstract}
Abstrak
Penggunaan pompa sebagian besar sebagai penggerak, conveyor, mesin press, elevator dan lainnya. Motor induksi yang paling banyak dipergunakan karena mesin induksi kuat, kokok dan mudah perawatannya serta efisiensi pada daya cukup tinggi. Permasalahan yang sering terjadi pada setiap electro motor adalah kerusakan mekanis seperti over-current (arus lebih), mechanical failure (kerusakan mekanis), tahanan isolasi yang rendah, pelumasan yang kurang, getaran berlebih, misalignment, umur motor dan faktor lain dalam operasi motor induksi, Data diperoleh melalui peneltian field research observasi langsung pada objek yang diteliti. Penelitian dilakukan dengan cara observasi di KM. Dharma Kartika IX. Berdasarkan hasil peneitian bahwa kerusakan pada komponen electro motor disebabkan oleh beberapa hal di antaranya arus lebih, kerusakan mekanis, tahanan isolasi yang rendah dan kelebihan panas.
\end{abstract}

Kata kunci $\quad$ : Electro Motor Oil Pump, Motor Induksi

\begin{abstract}
Penggunaan The use of pumps is mostly as a driver, conveyor, press machine, elevator and others. Induction motors are most widely used because they are strong, crowing and easy to maintain and their efficiency at power is high. The problems that often occur in each electro motor are mechanical damage, such as over-current, mechanical failure, low insulation resistance, insufficient lubrication, excessive vibration, misalignment, motor age and other factors. operation of the induction motor, data obtained through Field Research research direct observation of the object under study. The research was conducted by means of observation on the KM Dharma Kartika IX. Based on the research results that the cause of damage to the electro motor components is caused by several things: overcurrent, mechanical damage, low insulation resistance and excess heat.
\end{abstract}

Keywords: Electro Motor Oil Pump, Induction Motor

\section{Pendahuluan}

Electromotor merupakan alat elektromekanik yang dipergunakan dalam berbagai aplikasi industri untuk merubah energy listrik menjadi mekanik [1]. Electromotor pada umumnya dipergunakan untuk mengerakkan pompa, elevator, conveyor, mesin press, dan sebagainya.
Motor induksi paling banyak dipergunakan karena mudah perawatnnya, kuat, kokoh dan efisiensi daya cukup tinggi.

Permasalahan yang terjadi pada setiap electro motor adalah kerusakan mekanis yang dapat disebabkan oleh banyak hal seperti over-current (arus lebih), mechanical failure (kerusakan 
mekanis), low insulation resistance (tahanan isolasi yang rendah), kurang pelumasan, Getaran, sistem kurang seimbang, misalignment, umur alat dan faktor lain,.

Stres elektrik dan stres mekanik adalah salah contoh dari kerusakan sebagai akibat sistem pengoperasian electromotor. Stres mekanik terjadi karena beban berlebih dan perubahan beban yang tiba-tiba. Stres mekanik menyebabkan kerusakan bearing dan patahnya rotor bar. Stres elektrik sangat berhubungan dengan permasalahan sumber tegangan. Contoh motor induksi yang bersumber $\mathrm{AC}$ cenderung mengalami stres elektrik sebagai akibat frekuensi tinggi dari arus stator, tagangan lebih. Tagangan lebih disebabkan karena panjang kabel antar motor dan AC serta gelombang tegangan transien yang pantulankan. Stres elektrik ini dapat mengakibatkan hubung singkat belitan stator yang pada akhirnya menyebabkan kerusakan pada motor induksi.

Viskositas atau kekentalan pelumas dibagi secara menurut International Organization for Standardization (ISO). Pelumas umumnya berbentuk cairan, Pelumas berfungsi sebagai lapisan melindungi komponen mesin dai gesekan dan memisahkan dua permukaan yang saling berhubungan. Fungsi cairan (minyak lumas) adalah untuk menjaga suhu mesin pada tataran normal..

Pada saat suhu mesin yang tinggi kekentalan oli cenderung turun dan oli mengalami pemuaian volume, dan jika suhu mesin rendah kekentalan oli cenderung meningkat, dan oli mengalami penyusutan volume. Oli mengalami perubahan volume jika mengalami perubahan suhu.

Suhu pendingin yang tinggi dapat mengakibatkan naiknya Suhu minyak lumas, faktor lain yang dapat mengakibatkan suhu minyak lumas naik seperti terjadinya kebocoran sistem pembakaran yang masuk ke crank case, serta penggunaan minyak lumas yang sudah melampaui jam kerja atau minyak lumas yang sudah tidak layak pakai.

Pendinginan minyak pelumas agar supaya mencapai nilai kurang dari $450^{\circ} \mathrm{C}$ diper gunakan cooler. Cooler akan menurunkan suhu pelumas yang masuk ke mesin hingga mencapai harga $\leq$ $450^{\circ} \mathrm{C}$, Dalam mesin pelumas ditampung di oil pan (calter) kemudian masuk ke sump tank. Kecepatan fluida pada sistem pelumasan akan mencapai nilai $1,8 \mathrm{~m} / \mathrm{s}$. Pelumasan dari main engine dilengkapi dengan sensor untuk UMS (Unattended Machinery Spaces). Pemurnian menggunakan metode UMS ini menggunakan centrifuges otomatis dan total discharge. .

Pada Mesin Induk di KM. Dharma Kartika IX, pompa oli tidak akan bersirkulasi dan tidak akan bekerja jika motor penggerak (electromotor) tidak bekerja, sistem pelumasan sangat penting untuk menjaga suhu minyak lumas pada kondisi normal. Pelumasan yang baik dan benar akan efisien, komponen mesin tidak terjadi kerusakan dan mesin dapat beroperasi lebih lama. Sama halnya electromotor, motor penggerak elektro motor merupakan suatu komponen yang penting untuk menggerakkan mesin-mesin pompa.

Permasalahan dalam penelitian ini adalah : Faktor penyebabkan kerusakan electro motor oil max pump Mesin Induk di KM. Dharma Kartika IX. Sedangkan tujuan penelitian mengetahui faktor penyebab kerusakan electro motor oil max pump pada mesin induk di kapal KM. Dharma Kartika IX.

\section{Materi dan Metode \\ Electromotor Oil Max Pump (Pompa Oli)}

Pompa oli merupakan komponen yang penting dalam sistem pelumasan di kapal [2]. Pompa oli mempunyai fungsi untuk memberikan tekanan pada oli mesin sehingga oli mampu bersirkulasi ke seluruh sistem pelumasan mesin. Pompa oli menghisap oli dari Tangki Oli yang sudah terkumpul kemudian dipompa sehingga oli mesin yang ada dijalur sistem pelumasan mempunyai tekanan. Tekanan pada oli ini, akhirnya membuat oli mesin bergerak keseluruh sistem pelumasan dan melumasi komponenkomponen mesin. Setelah terjadi pelumasan, oli mesin ditampung kembali pada bak penampungan oli dan kemudian disirkulasikan kembali. Pada sebuah mesin terdapat banyak bagian yang mengalami gesekan seperti metal, torak, roda gigi yang dikenakan gaya gesek yang mengganggu gerakannya. Karena gaya ini, bagian yang bergerak menjadi aus sehingga kedudukannya rongga atau malah melekat sehingga tidak dapat bergerak lagi. Jika gesekannya besar akan terjadi pemborosan tenaga penggerak mesin. Untuk mengurangi gesekan agar mencegah ausnya atau melekatnya bagian-bagian yang bergesekan dibutuhkan 
pelumasan dengan memberikan bahan minyak lumas pada permukaan-permukaan yang bergesekan, selain melumasi bagian-bagian yang akan bergesekan harus dibuat dari bahan yang sesuai.

Tipe dasar dari komponen pompa oli pada sistem pelumasan yang umum digunakan pada mesin-mesin ialah [3] :

\section{a. Sistem Carter Basah}

Pada sistem carter casah, bagian bawah dari pada piringan merupakan tangki supply dan alat pendingin pelumas. Minyak lumas jatuh menetes dari silinder dan bantalan dan kembali ke dalam tanki, kemudian dialirkan kembali oleh sebuah pompa minyak lumas kedalam sistem carter basah,. Sistem sump tank basah banyak digunakan pada mesin-mesin kecil.

\section{b. Sistem Carter Kering}

Minyak lumas yang mengalir ke dalam sump tank selanjutnya di alirkan oleh sebuah pompa minyak lumas melewati sebuah filter, kemudian dikembalikan lagi ke dalam tangki supply. Tangki supply ditempatkan di luar mesinnya, kapasitas yang dimiliki pompa cukup besar sehingga sump tanknya atau tangki dapat dikosongkan sama sekali. .

Sistem carter kering menggunakan oil cooler, oil cooler ada yang menggunakan air, dan ada yang menggunakan udara sebagai medium pendinginnya. Sistem cooler kering ini banyak digunakan pada mesin stasioner yang besar seperti di kapal maupun di darat. Berdasarkan cara mengalirnya oli ke komponen yang perlu dilumasi, terdapat tiga sistem yang umumnya di gunakan yaitu sistem percik, sistem tekan, dan sistem kombinasi[3]:

\section{Sistem Percik}

Oli sampai yang sampai ke bagian yang dilumasi dengan cara dipercikkan oleh ujung pipa engkol, ujung pipa engkol diberi alat pemercik yang dengan rancangan khusus, percikkan oli akan sedemikianrupa dapat melumasi dinding silinder dan bearing.

2. Sistem Tekan

Pada sistem tekan oli dialirkan ke komponen yang dilumasi, dengan cara dipompa. Dibuat komponen pada mesin saluran-saluran kecil sebagai jalan dan tempat aliran oli.

3. Sistem Kombinasi

Sistem kombinasi adalah gabungan antara metoda percik dan metoda tekan. Bila sistem tekan tak bekerja, misalkan karena rusak maka sistem percik bisa berlangsung untuk melakukan pelumasan pada batas-batas tertentu.

\section{Faktor Penyebab Kerusakan Electro Motor Pompa Oli}

Bantalan/bearing merupakan komponen paling sering mengalami kerusakan, kerusakan pada bearing berdasarkan lokasi, dapat diklasifikasikan menjadi kerusakan inner-race dan outer-race [4]. Bearing merupakan suatu komponen mesin yang menumpu dan membatasi gerakan poros, dan putaran atau gerakan bolakbaliknya dapat terjadi secara halus dan aman. Pada umumnya konstruksi bearing terdiri dari 4 bagian penting, yaitu outer race, inner race, ball, dan cage. Penyebab utama kerusakan bearing antara lain; hilangnya minyak pelumas, tercemarnya pelumas, beban berlebih dan panas berlebih (overheating).

Penelitian sebelumnya, dari Electric Power Research Institute (EPRI) yang meneliti 6312 motor dan Riset dari Motor Reliability Working Group IEEEIAS yang meneliti 1141 motor menyimpulkan bahwa kerusakan bearing berdasarkan lokasinya dapat diklasifikasikan menjadi kerusakan inner-race dan outer-race [1]. Sementara itu penyebab utama kerusakan bearing adalah hilangnya minyak pelumas, tercemarnya pelumas, beban berlebih dan panas berlebih. Kerusakan belitan dapat terjadi sebagai akibat panas berlebih, voltage stress, getaran mekanik, abrasi dan gesekan antara stator dan rotor.

Lemahnya isolasi pada belitan dapat mengakibatkan hubung singkat antar belitan dan belitan dengan ground. Kemungkinan Hubung singkat akan lebih terjadi jika factor keamanan berkurang contoh belitan yang tidak sempurna dan sistem isolasi yang seadanya[5][7] hal ini pada akhirnya sangat berpengaruh terhadap keselamatan pelayaran.

Terdapat dua tipe kerusakan rotor yang dihubungkan dengan rotor sendiri antara lain; retak atau patahnya rotor bar karena panas berlebih, hot-spot atau kelelahan (fatigue), stress saat operasi transien (start-up). Bahan dalam pembuatan materi rotor sangat berpengaruh dalam ketahanan terhadap panas, benturan mekanis dan panas tentunya. Hal inilah yang mesti diperhatikan karena kerusakan suatu bahan tidak terlepas dari sifat bahan itu sendiri. Tipe kedua merupakan yang berhubungan dengan air-gap eccentricity. Air-gap eccentricity. 
Beban tidak seimbang yang berlangsung lama akan mengakibatkan kerusakan bearing dan rumah bearing yang dapat mempengaruhi simetrisnya air-gap. Pemakaian terus menerus tentunya akan mengakibatkan keausan bahkan kerusakan, disini umur suatu alat menjadi ukuran[8].

Kenaikan suhu [9] atau overheating pada Rotor motor induksi pada umumnya disebabkan kejadian rugi-rugi pada sistem motor itu sendiri. Rugi-rugi pada konduktor kumparan stator dan rotor yang dialiri arus merupakan sumber panas yang paling utama Tatapi panas yang timbul pada poros, casing stator, celah udara dipermukaan rotor maupun bagian lainnya merupakan manifestasi dari perpindahan panas belitan rotor dan belitan stator, dan merupakan perpindahan konduksi, konveksi maupun radiasi.

Pada motor induksi rotor sangkar, bagian yang berhubungan panas adalah bagian stator, sebab bagian stator terdapat belitan yang memiliki batas ketahanan terhadap suhu yang jauh lebih rendah dibandingkan pada rotor. Pada motor induksi rotor, sangkar, panas yang perlu mendapat perhatian adalah bagian stator. Kenaikan panas disebebkan beberapa faktor antara lain; Jenis pendinginan, Perpindahan panas, suhu lingkungan dan beban.yang berlebih.

Metode yang digunakan dalam mendeteksi kerusakan Electromotor [10] adalah :

\section{Noise Monitoring}

Sinyal spektrum akustik noise (suara) dari air-gap eccentricity dipergunakan untuk menentukan kerusakan. Akan tetapi pengukuran noise ini secara tidak akurat karena bunyi pengganggu dari lingkungan sehingga banyak noise yang masuk ke peralatan dan ikut dalam pengukuran

2. Torque Monitoring

Kebanyakan kerusakan elektromotor mengakibatkan harmonisa dengan frekuensi tertentu. Beberapa penelitian tentang torsi airgap memakai parameter tegangan terminal, dan pengukuran tentang kondisi rotor, poros dan beban mekanik dari motor untuk menentukan jumlah torsi airgap. Cara ini mendeteksi retak rotor bar, stator unbalance sebagai akibat kerusakan belitan. Namun cara ini kurang akurat saat reaktansi magnetik bocor dan alur magnetik dari ketiga fasa menjadi kurang simetris.

\section{Flux Monitoring}

Penelitian terhadap flux memberikan petunjuk yang akurat tentng kondisi mesin. Pada penelitian yang serius dengan peralatan flux menunjukan perubahan pada airgap, belitan, tegangan dan arus tercermin dalam spektrum harmonisa. Dikarenakan airgap memerlukan modifikasi perancangan karena ukuran yang kecil sehingga sulit diimplementasikan.

4. Vibration Monitoring

Cara ini cukup memadai untuk memenutukan kerusakan mekanik, Kerusakan mekanik menciptakan harmonisa yang cukup unik dengan frekuensi berbeda sehingga perbedaan inilah yang dipergunakan untuk mendeteksi kerusakan mekanik electromotor karena ada perbedaan juga dalam level daya dalam sinyal vibrasi. Sinyal getaran diukur menggunakan sensor getaran yang dipasang pada frame stator dan spektrum yang dihitung dengan Fast Fourrier Transform (FFT). Spesifik harmonic dipergunakan untuk menentukan kerusakan apa yang terjadi dalam electro motor.

\section{Current Monitoring}

Cara ini paling yang paling banyak digunakan. Pengkuran arus stator dari motor sudah sesuai untuk proteksi mesin terhadap arus lebih, arus ke tanah yang sangat merusak. .Terdapat tiga cara yang sudah dilaksanakan oleh banyak peneliti antara lain; zero-sequence, negative sequence, Park's vector, dan Current Spectral Analysis. Ketiga cara tersebut disebut Current Signature Analysis (CSA) adalah yang paling banyak dipergunakan.

\section{Metode}

Penelitian dilaksanakan di KM. Dharma Kartika IX milik perusahaan PT Dharma Lautan Utama mulai tanggal 17 Januari 2020 sampai dengan tanggal 25 Juni 2020.

Peralatan yang digunakan dalam penelitian

1. Kunci Shock: Sebuah kunci yang berbentuk lubang tabung yang pada sisi tengahnya telah terlubangi sesuai dengan ukuran diameter baut yang akan di buka.

2. Kunci Ring dan Pas: peralatan dipergunakan supaya ada energi tambahan yang lebih besar pada baut dan mur terdapat lengan agak panjang baik untuk membuka maupun untuk mengencangkan.

3. Vernier Caliper: peralatan pengukur teknik yang dapat dipergunakan untuk mengukur 
tiga jenis pengukuran sekaligus dalam satu alat menggunakan metode geser.

4. Avo meter/Ohm meter: dipergunakan dalam pengukuran tegangan atau hambatan sebuah lilitan electromotor atau pada rangkaian kelistrikan.

Teknik pengumpulan data menggunakan metode-metode yang sistematis dalam melakukan penelitian. Hal ini dimaksudkan guna memberikan informasi yang lengkap, serta memberikan data-data yang akurat dan bersifat obyektif serta dapat dipertanggung jawabkan. Untuk meneliti permasalahan penyebab kerusakan electromotor oil max pump pada mesin induk diatas kapal KM. Dharma Kartika IX, penulis mengolah data empiris dan data teoritis untuk dijadikan tolak ukur.

Teknik pengumpulan data yang dipergunakan peneliti ini antara lain: observasi, studi pustaka, wawancara dan dokumentasi. Pengamatan/ Observasi merupakan penelitian dengan cara pengamatan langsung pada objek yang diteliti [11]. Peneliti mengamati secara langsung objek dari penyebab terbakarnya electromotor pada pompa oli mesin induk. Peneliti mengamati masalah-masalah yang terjadi pada pompa oli mesin induk yang tidak bekerja maksimal ketika electromotor Mesin Induk di kapal KM. Dharma Kartika IX rusak. Teknik studi pustaka merupakan teknik kolektivitas data yang dipergunakan peneliti mengambil dari bukubuku referensi yang membahas tentang komponen-komponen mesin induk dan pesawat bantu. Wawancara merupakan suatu cara pengumpulan data dengan bertanya langsung kepada orang yang menguasai subyek sebagai narasumber penelitian [12]. Teknik Wawancara ini dilakukan oleh peneliti melalui berbagai pertanyaan yang diberikan kepada narasumber (Masinis \& Electricion). Dokumentasi adalah cara mengoleksi data kualitatif dengan menganalisis dokumen-dokumen yang berhubungan dengan obyek penelitian [13]. Teknik ini digunakan peneliti guna memperoleh data dan informasi dalam bentuk gambar/foto komponen mesin yang rusak, seperti electromotor oil max pump Mesin Induk di Kapal KM. Dharma Kartika IX.

\section{Hasil Dan Pembahasan}

Faktor penyebab kerusakan electromotor oil max pump Mesin Induk di KM. Dharma Kartika IX adalah Kerusakan rotor motor induksi yang disebabkan oleh beberapa hal seperti kerusakan mekanis, arus berlebih dan Overheating.

Tabel 1. Hasil Observasi Data Electromotor Oil Pump KM. Dharma Kartika IX yang Normal

\begin{tabular}{|c|c|c|c|}
\hline $\begin{array}{c}\text { ELMOT } \\
\text { PUMP }\end{array}$ & SUHU & KINERJA & $\begin{array}{l}\text { PERAWA- } \\
\text { TAN }\end{array}$ \\
\hline 1 & $50^{\circ} \mathrm{C}$ & $\begin{array}{l}\text { Electromot } \\
\text { or Normal } \\
\text { Dan Isapan } \\
\text { Tekanan } \\
\text { Pompa Oli } \\
\text { Normal }\end{array}$ & $\begin{array}{l}\text { Membersihk } \\
\text { an Filter LO } \\
\text { Cooler dan } \\
\text { Pemeriksaan } \\
\text { Panel Alarm } \\
\text { Dengan } \\
\text { Waktu } \\
\text { Tertentu }\end{array}$ \\
\hline 2 & $50^{\circ} \mathrm{C}$ & $\begin{array}{l}\text { Electromot } \\
\text { or Normal } \\
\text { Dan Isapan } \\
\text { Tekanan } \\
\text { Pompa Oli } \\
\text { Normal }\end{array}$ & $\begin{array}{l}\text { Membersihk } \\
\text { an Filter LO } \\
\text { Cooler dan } \\
\text { Pemeriksaan } \\
\text { Panel Alarm } \\
\text { Dengan } \\
\text { Waktu } \\
\text { Tertentu }\end{array}$ \\
\hline 3 & $50^{\circ} \mathrm{C}$ & $\begin{array}{l}\text { Electromot } \\
\text { or Normal } \\
\text { Dan Isapan } \\
\text { Tekanan } \\
\text { Pompa Oli } \\
\text { Normal }\end{array}$ & $\begin{array}{l}\text { Membersihk } \\
\text { an Filter LO } \\
\text { Cooler dan } \\
\text { Pemeriksaan } \\
\text { Panel Alarm } \\
\text { Dengan } \\
\text { Waktu } \\
\text { Tertentu }\end{array}$ \\
\hline 4 & $50^{\circ} \mathrm{C}$ & $\begin{array}{l}\text { Electromot } \\
\text { or Normal } \\
\text { Dan Isapan } \\
\text { Tekanan } \\
\text { Pompa Oli } \\
\text { Normal }\end{array}$ & $\begin{array}{l}\text { Membersihk } \\
\text { an Filter LO } \\
\text { Cooler dan } \\
\text { Pemeriksaan } \\
\text { Panel Alarm } \\
\text { Dengan } \\
\text { Waktu } \\
\text { Tertentu }\end{array}$ \\
\hline
\end{tabular}

Tabel 2. Hasil Observasi Data Electromotor Oil

Pump Kapal KM. Dharma Kartika IX yang

Tidak Normal/Mengalami Kerusakan.

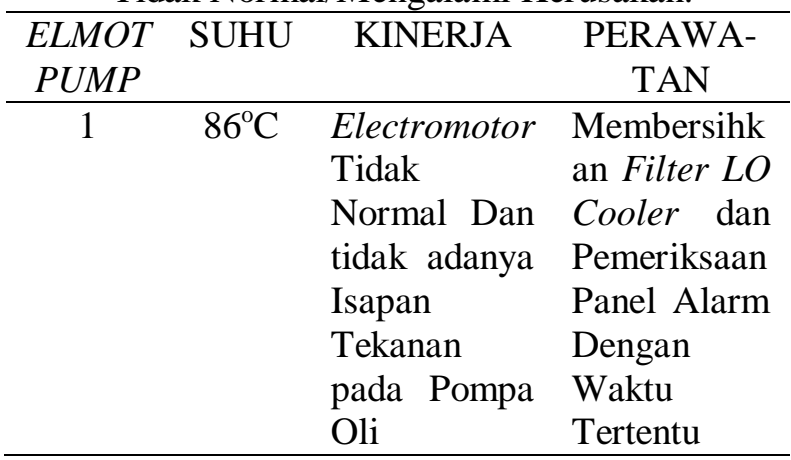

Sebagaimana diketahui bahwa pompa oli pada mesin induk sangat berperan penting untuk 
kelancaran dari operasi mesin sesuai dengan pengalaman peneliti selama melaksanakan penelitian diatas kapal KM. Dharma Kartika IX. Saat itu kapal mulai berangkat dari Pelabuhan Tanjung Perak (Surabaya) menuju Pelabuhan Trisakti (Banjarmasin) tepatnya pada tanggal 07 Maret 2020.

Pada saat keluar dari perairan tanjung perak Surabaya tiba-tiba terjadinya kepulan asap pada electromotor oil max pump main engine dan seketika kecepatan mesin induk menurun. Kejadian ini terjadi pada pukul 14.20 saat jam jaga 12:00 - 16:00 dimana yang jaga pada waktu itu masinis II (dua) dan langsung melapor pada KKM. kemudian KKM langsung menghubungi Captain bahwa putaran mesin akan diturunkan untuk mencegah panas yang berlebihan sampai dipindahkan ke kerja pompa oli cadangan agar mesin dapat dijalankan lagi dengan keceapatan normal.

Sebelum rusaknya electromotor pompa oli Mesin Induk Kapal KM. Dharma Kartika IX, Pada saat itu pompa dalam kondisi bekerja dengan baik tiba- tiba isapan pada pompa oli turun dari tekanan luuar tidak normal.. Oiler jaga mengetahui hal tersebut langsung menghidupkan pompa oli mesin induk nomor dua dan langsung mematikan pompa bermasalah. Ketika pompa nomor dua bekerja normal, kemudian melaporkan peristiwa kepada masinis jaga yang kemudian dilaporkan ke masinis yang bertanggung jawab. Berdasarkan laporan maka segera mengecek dan meneliti pompa dengan membawa alat yang dibutuhkan.

Masinis mengecek Cover pompa oli dan electromotor pada pompa dan setelah diteliti electro motor memang sudah harus di perbaiki dan dibersihkan karena banyak terdapat kotoran dan kerak. Perbaikan dan perawatan dilakukan dan setelah selesai dilakukan uji coba apakah pompa sudah dapat digunakan secara normal. Tetapi setelah dicoba berkali kali isapan yang di hasilkan masih tetap tidak berubah.

Pengecekan pada sistem instalasi pompa oli dan electromotor dilakukan oleh masinis agar supaya dapat menemukan penyebabnya, akan tetapi tidak ditemukan kerusakan pada sistem instalasi pompa oli. Setelah diteliti ditemukan terbakarnya rotor pada electromotornya.

Masinis pada akhirnya melaporkan kerusakan ini kepada kepala kamar mesin (KKM) dan mengusulkan untuk diadakan perbaikan secara menyeluruh (overhoul) terhadap electromotor tersebut. Berdasarkan data tersebut diatas KKM bersama perwira mesin mengadakan analisa secara cermat tentang menurunnya kinerja dari pompa oli yang menyebabkan electromotor rusak. Berdasarkan kejadian ini peneliti mengambil kesimpulan bahwa penyebab rusaknya electro motor oil max pump pada mesin induk di Kapal KM. Dharma Kartika IX adalah Rotor terbakar. Rotor adalah komponen yang sangat penting pada sebuah motor induksi, kerusakan rotor akan mengakibatkan cacat pada konduktor motor induksi. Jika konduktorkonduktor mengalami kerusakan akan membuat rotor mengalami gesekan berlebih dan terjadinya panas. Pada saat electromotor mengalami hal ini maka dapat dipastikan kinerja mesin tidak bisa mencapai optimal.

Kerusakan pada komponen di atas kapal merupakan bagian yang komprehensif karena dapat mengganggu kinerja mesin induk. Kinerja mesin induk bagian utama dalam kesuksesna suat perjalanan kapal[8], [14]-[17].Kebisingan dan kebesihan kapal menjadi sesuatu yang harus diperharikan agar nyaman bekerja di kamar mesin[5], [18]-[20].

Berikut ini merupakan permasalahan yang paling sering terjadi pada Electromotor :

1. Kerusakan Mekanis (Mechanical Failure)

Penyebab kerusakan mekanis karena kurang pelumasan, getaran berlebih dan tidak seimbang, atau karena misalignment. Penyebab- ini memiliki kesamaan, yaitu terjadi secara bertahap dan menunjukkan tanda-tanda peringatan. Bunyi gangguan (noise) dapat menunjukan tanda tanda awal dari kerusakan mekanis. Analisa terhadap sampel oli merupakan salah satu yang mengindikasikan bahwa terdapat kerusakan. Tindakan preventif segera yang tepat dapat mencegah kerusakan pada motor.

2. Tahanan Isolasi Rendah (Low Insulation Resistance)

Lilitan motor dan sistem isolasi dari listrik akan turun seiring dengan waktu. Contohnya sebuah motor induksi yang baru pada umumnya akan memiliki tahanan isolasi (diukur dengan megger) diatas 1000 megohm. Umur motor akan menusut karena pemakaian yatu Jika motor tersebut bekerja maka nilai tahanan isolasi akan turun hingga batas 
terendah dan tidak memungkinkan motor bekerja (short).

Berdasarkan kesepakatan bahwa nilai tahanan isolasi kurang dari 1 megohm adalah batas aman untuk motor harus segera direfurbish. Beberapa faktor yang mempengaruhi laju penurunan tahanan isolasi antara lain: Faktor lingkungan yang perlu diperhatikan adalah ventilasi ruang motor, apakah telah sesuai dengan standar air change rate at. Pada beban, dapat diperiksa apakah pendinginan motor bekerja dengan baik. Pendinginan motor dapat berupa injection cooling (pada kompresor refrigerasi) , radiator, atau kipas yang ikut berputar bersama shaft motor.

\section{Kerusakan Bearing (Bantalan)}

Kerusakan bearing merupakan hal yang sering terjadi dan mengakibatkan gulungan electro motor terbakar, Bantalan (bearing) yang rusak, akan mengakibatkan putaran shaft menjadi lebih berat, dan pada akhirnya ampere motor menjadi berlebih, serta suhu pada kawat gulungan akan tinggi . Bila hal ini terjadi akan merusak isolasi kawat dan terjadi short sircuit dan parahnya akan mengakibatkan gulungan terbakar.

\section{Over-Current (Arus Lebih)}

Kejadian Over-current karena sistem operasi yang mengakibatkan motor menarik arus lebih besar dari kemampuannya (rated capacity). Pada umumnya sulit diprediksi kapan akan terjadi Terdapat alat yang mampu membatasi atau mencegah over-current seperti phase failure relay, overload, under voltage relay, fuse dan sebagainya. Peralatan ini sebuah kewajiban ada di instalasi motor listrik sebagai proteksi keselamatan listrik

\section{Panas Berlebih (Overheating)}

Overheating adalah suatu kondisi suhu mesin melebihi batas normal, Panas berlebih dapat diketahui melalui indikator suhu. Pengabaikan fungsi indikator suhu sering terjadi sehingga tidak peduli seberapa tinggi suhu mesin. Menjaga suhu mesin tetap normal merupakan hal yang penting dan merupakan keharusan karena dapat terjadi kerusakan fatal pada komponen mesin jika mesin sampai mengalami overhating

\section{Kesimpulan}

Dari analisis dapat ditarik kesimpulan sebagai berikut:Penyebab kerusakan electro motor oil max pump Mesin Induk di KM. Dharma Kartika IX adalah Kerusakan rotor motor induksi yang disebabkan adanya arus berlebih, dan di sebabkan oleh beberapa hal. Salah satunya stator terbakar, bearing rusak, kurang presisinya suatu bantalan motor, sehingga terjadi Overheating pada electro motor.

\section{Ucapan Terima Kasih}

Penulis mengucapkan terima kepada segenap pihak dari KM. Dharma Kartika IX atas dukungannya dalam kegiatan ilmiah ini dan menjadi tempat terselenggaranya penelitian.

\section{Daftar Pustaka}

[1] Yudiastawan, "Deteksi Kerusakan Bearing dan Ecceentricity Pada Motor Induksi Tiga Fasa dengan Current Singnature Analysis. In :," Fak. Mat. Ilmu Pengetah. Alam Progr. Magister Fis. Depok, 2009, doi: 10.15957/j.cnki.jjdl.2009.07.004.

[2] Rasyid, "Prinsip Pelumasan," Gramedia Pustaka Utama, 2001.

[3] B. H. Wijaya, "Type Pelumasan Mesin Induk," Jakarta Lib. Pustaka, 2010.

[4] A. Khamdilah and Djajari, "Analisa Pengaruh Tinggi Rendahnya Tekanan Minyak Lumas Pada Pompa Elektromotor Terhadap Pelumasan Mesin Induk," GEMA Marit., vol. 19, no. 1, pp. 20-27, 2017.

[5] A. Hendrawan, "Program Kesehatan Dan Keselamatan Kerja Di Atas Kapal," J. Sains Teknol. Transp. Marit., vol. 2, no. 1, pp. 110, 2020.

[6] A. Hendrawan, "Analisa Indikator Keselamatan Pelayaran Pada Kapal Niaga," J. Saintara, vol. 3, no. 2, 2019.

[7] D. Suryani, A. Y. Pratiwi, Sunarji, and A. Hendrawan, "Peran Syahbandar Dalam Keselamatan Pelayaran," J. Saintara, vol. 2, no. 2, 2018.

[8] A. Hendrawan, "Analisa Pengebab Keausan Poros Baling Baling Kapal," J. Saintara, vol. 4, no. 1, 2019.

[9] C. Mademlis, I. Kioskeridis, and T. Theodoulidis, "Optimization of single-phase induction motors - Part I: Maximum energy efficiency control," IEEE Trans. Energy 
Convers., vol. 20, no. 1, pp. 187-195, 2005, doi: 10.1109/TEC.2004.842386.

[10] F. E. Huang H and W. J.C, "Optimal placement of the run capacitor in single phase induction motor designs," IEEE Trans. energy Convers., vol. 3, no. 3, pp. 647-652, 1988.

[11] Arikunto, "Metode Penelitian Pengumpulan data," Jakarta PT. Rineka Cipta, p. 2006, 2006.

[12] Mardalis, "Metode Penelitian Suatu data," Jakarta Bumi Aksara, 2003.

[13] H. Herdiansyah, "Metode Penelitian Kualitatif untuk Ilmu-ilmu Sosial. Jakarta: Salemba Humanika," J. Non Form. Educ. Community Empower., vol. 1, no. 1, p. 2010, 2010.

[14] A. Hendrawan, "Analisa Tingkat Kebisingan Kamar Mesin Pada Kapal," WIJAYAKUSUMA Pros. Semin. Nas. Jar. Penelit. Cilacap "Menuju Cilacap 4.C (Creativity, Crit. Thingking, Commun. Colab., pp. 10-15, 2020.

[15] A. Hendrawan, "Pengaruh Turbocharger terhadap Daya Mesin Induk KN. Prajapati," Maj. Ilm. Gema Marit., vol. 22, no. 1, pp. 44-48, 2020, doi: 10.37612/gemamaritim.v22i1.50.

[16] D. Suryani and A. Hendrawan, "Studi Tentang Sanitasi Kapal," J. Saintara, vol. 4, no. 2, 2020.

[17] A. Hendrawan, L. Lusiani, and R. Aprilian, "Sandblasting pada kapal mv. berlian indah," J. Saintara, vol. 4, no. 2, pp. 26-33, 2020.

[18] A. Hendrawan, "Kebisingan di Kapal KN Parajapati," Maj. Ilm. Bahari Jogja, vol. 18, no. 2, pp. 19-25, 2020.

[19] A. Hendrawan and A. K. Hendrawan, "Analisa Kebisingan di Bengkel Kerja Akademi Maritim Nusantara," J. Saintara, vol. 5, no. 1, pp. 1-5, 2020.

[20] A. Hendrawan, "Konsep Kapal Dengan Tenaga Otec (Ocean Thermal Energy Conversion)," Semin. Nas. Marit. Politek. Bumi Akpelni, pp. 1-5, 2019. 